Gabriel Salazar, Mercaderes, Empresarios y Capitalistas (Chile, Siglo XIX) (Santiago: Edit. Sudamericana 2009), 794 páginas.

\title{
COMENTARIO AL LIBRO DE GABRIEL SALAZAR MERCADERES, EMPRESARIOS Y CAPITALISTAS (CHILE, SIGLO XIX)
}

\section{Rolf Lüders}

El libro Mercaderes, Empresarios y Capitalistas del historiador Gabriel Salazar es el complemento natural de su obra Labradores, Peones y Proletarios. Formación y Crisis de la Sociedad Popular Chilena del Siglo XIX (1985). En la última Salazar describe con gran elocuencia las condiciones de trabajo y vida de las clases populares chilenas en el siglo antepasado, que tilda como "el desgarramiento histórico inmisericorde de la clase popular"1. En el prólogo al libro acá comentado Salazar se pregunta "cómo un orden político tan célebre, apolíneo y patriótico como el portaliano" 2 , al mismo tiempo que tan alabado por las clases dirigentes durante gran parte de nuestra historia, "pudo producir ese desgarrador resultado" 3 .

La anterior es la pregunta principal que el autor pretende responder en las casi 800 páginas siguientes, en que - más que relacionar las características que en la actualidad se le atribuyen al orden portaliano

Rolf LüDERs. Ph. D. Economía, Universidad de Chicago. Profesor titular del Instituto de Economía, Pontificia Universidad Católica de Chile (PUC). EHClioLab, PUC.

Palabras clave: historia económica; economía; historia.

${ }^{1}$ Salazar (2009), p. 10.

${ }^{2}$ Ibíd.

${ }^{3}$ Ibíd. 
con los resultados del quehacer económico para las diferentes clases sociales del país - relata una serie de historias, varias de ellas extraordinariamente interesantes, que sugieren las nefastas consecuencias del desmedido afán de lucro del empresariado, especialmente del local pero también del foráneo, sobre el desarrollo de la economía y, en particular, para los artesanos y otros pequeños empresarios.

El libro es una historia económica del siglo XIX. Evidentemente es una historia incompleta, como lo son en estricto rigor todas las historias. En este caso el relato se centra en el desarrollo de las grandes empresas y los empresarios, pero sin descuidar las interrelaciones con otros actores: los empresarios pequeños, las autoridades de gobierno y los trabajadores.

La aproximación de Gabriel Salazar a la historia económica es, naturalmente, muy distinta a la de un economista. No explicita el "modelo" económico que subyace en los juicios que emite - y vaya que éstos son fuertes, como quedará en evidencia a lo largo de este comentario- $y$, en general, no pretende medir el fenómeno económico. En efecto, su tesis y sus opiniones generalmente no concuerdan con los datos agregados existentes para el período que estudia.

En especial, en el siglo XIX la economía chilena creció a una tasa mayor que la del resto del mundo, mayor que la de EE.UU. y mayor que la de cualquier otro conglomerado de países. Al mismo tiempo y a partir de 1850 , desde cuando se obtienen los primeros datos que permiten hacer estimaciones al respecto, la pobreza parece haber disminuido espectacular y constantemente, hecho que es coherente con la tasa de crecimiento económico relativamente elevada, pero contradice el cuadro que nos pinta Salazar en su libro. El anterior resultado se obtuvo a pesar de que la distribución del ingreso se hizo más desigual, fenómeno que es coherente con la experiencia histórica de otros países cuando alcanzaron los niveles de ingreso per cápita que Chile tuvo entonces ${ }^{4}$.

En las próximas secciones se describirá la obra de Salazar, se hará un breve análisis de las diferencias metodológicas entre historiadores y economistas y se inspeccionará la información relevante disponible, se analizarán algunos pasajes escogidos del libro y se concluirá.

\footnotetext{
${ }^{4}$ Prados (2005)
} 


\section{Estructura y contenido del libro}

Mercaderes, Empresarios y Capitalistas describe —en siete capítulos - ciertos procesos y/o episodios históricos que el autor considera claves, pero que no necesariamente se suceden uno al otro en el tiempo. En general, hay superposición entre ellos y en un caso incluso uno de los procesos se desarrolla íntegramente dentro de un subperíodo de otro.

El primer capitulo, que es absolutamente fascinante, se refiere al entierro y desentierro del tesoro mercantil de Juan Antonio Fresno y busca relatar el ambiente existente en los alrededores de Santiago entre 1772-1837. Pinta un cuadro en que deja en evidencia los valores de los empresarios de la época como de la clase dirigente en general (caballeros, dispuestos a pagar por pertenecer al círculo dirigente), el pésimo trato (abuso) que recibían los trabajadores (peones), las aparentemente enormes rentabilidades del capital (éste se triplicaba cada tres años), el gran diferencial de rentabilidad entre las actividades comerciales y las "productivas", y la inseguridad existente. Salazar refiere a la escasez de dinero, que atribuye al atesoramiento que hacían del mismo los capitalistas, que literalmente enterraban el dinero y las joyas para evitar que se los robaran y/o que el Estado se los confiscara directa o indirectamente. Concluye Salazar: "Fue este pavor (se refiere al pavor político producido por el militarismo patriota y el desorden público) que despertó en ellos el nervioso afán por construir un sistema político de seguridad nacional para proteger sus actividades comerciales y sus respectivos tesoros. Sería el pensamiento base y la obra política del mercader Diego Portales" 5 .

El segundo capítulo relata la transformación económica de Chile después de 1810, en que el país se abre al intercambio internacional. Para ello describe, con gran lujo de detalles, la institución de los consignees (consignatarios) y su evolución hacia subsidiarias de casas comerciales extranjeras y empresas exportadoras de minerales, desplazando en estas funciones a los agentes locales. En particular, sugiere, sin expresarlo, que: (a) las empresas inglesas vaciaron sobre América Latina los bienes que no podían colocar en sus mercados tradicionales, (b) para hacerlo negociaron acceso de mercado con las autoridades nacionales logrando su objetivo a menudo bajo presión, y (c) las negociaciones se

\footnotetext{
${ }^{5}$ Salazar (2009), p. 53.
} 
hicieron con el apoyo de la Royal Navy, estacionada frente a nuestras costas. Salazar hace referencia al fracaso de varias iniciativas manufactureras - generalmente locales - que sucumbieron frente a la competencia extranjera. Destaca que “gobernantes como Bernardo O'Higgins, Agustín de Eyzaguirre, Diego Portales o Manuel Montt [...] no sólo permitieron, sino que alentaron y aún protegieron a los comerciantes extranjeros en desmedro de los intereses estratégicos del país"6.

En general, a pesar de la forma en que Salazar presenta la información en este capítulo, pareciera que existió entre nacionales y extranjeros un ambiente muy favorable a una política económica liberal. Ya en 1821 se formó "una Comisión mixta para el reestudio del Reglamento de Libre Comercio", comisión que trató "de conciliar las ventajas del comercio y menores trabas del comerciante con el cobro proporcionado

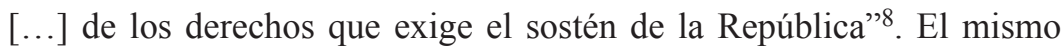
Salazar señala que en aquella época "todos los mercaderes concordaron - chilenos y extranjeros - en que el principio que los regía de modo supremo era el "liberalismo""9. Agrega: "los gobernantes criollos [...] no pudieron menos que asumir el discurso librecambista [...] evidente durante la dictadura de Bernardo O'Higgins, dudosa durante los gobiernos liberales, se volvió franca e institucional desde que se instaló el régimen portaliano" ${ }^{10}$. En efecto, durante los años 1930 y posteriores se firmaron tratados de libre comercio con EE.UU. e Inglaterra.

Salazar termina ese capítulo citando un escrito que un comerciante importante — José de Trucíos - envió en 1819 al Senado de la República, en que denuncia la forma en que los extranjeros, ingleses y norteamericanos llevaron el país al librecambismo y estarían arruinando a los agentes económicos locales. No obstante, la evidencia anterior sugiere que la visión de Trucíos fue más bien la excepción.

El tercer capitulo se refiere al problema de la escasez de dinero en Chile en el período 1810-1846, que Salazar atribuye al "intercambio desigual", que se tradujo en la exportación de metal y — sostiene - la consiguiente "contracción y sequía" del sistema monetario. Es un capítulo lleno de estadísticas sobre comercio y dinero, que sin una teoría

\footnotetext{
${ }^{6}$ Ibíd., p. 133.

${ }^{7}$ Ibíd., p. 145.

${ }^{8}$ Ibíd.

${ }^{9}$ Ibíd., pp. 146-147.

${ }^{10}$ Ibíd., p. 155.
} 
para respaldar el análisis, carece de interés. Sus conclusiones — que "la sequía monetaria afectaba principalmente a los productores del mercado interno que no exportaban su producción y a la clase asalariada en general"11_ no tienen sustento alguno en el texto. El problema de la escasez de monedas divisionarias, que es de interés, será analizado más adelante.

El cuarto capitulo, que abarca gran parte del libro y cubre el período 1823-1885, relata el conflicto que — según Salazar - se produjo entre los micro-empresarios y el patriciado mercantil y que terminó por aniquilar a los primeros. Entre 1843 y 1910 alrededor de 250.000 peones emigraron del núcleo central del país en búsqueda de mejores oportunidades. Otros pobres, sin embargo, optaron por crear empresas y generaron el primer proceso industrial del país. Se trataba, en realidad, de actividades artesanales, que utilizaban tecnologías localmente desarrolladas. Salazar sostiene - basado en cifras de importaciones de maquinaria- que las políticas librecambistas, impulsadas por los extranjeros y los mercaderes locales asociados a los anteriores, alentaron la importación de bienes y las actividades industriales basadas en tecnologías modernas, especialmente después de los años $1860^{12}$. Es esta moderna industrialización basada en maquinarias de alta tecnología la que habría destruido a las actividades artesanales, transformando a los maestros en operarios de las nuevas industrias. El fenómeno del estancamiento artesanal fue efectivo: según los datos proporcionados por Salazar, en 1854 el 26,5 por ciento de la clase trabajadora popular estuvo constituida por artesanos, en 1875 este porcentaje cayó a 16,1 por ciento.

El mismo capítulo relata detalladamente y en forma plausible la interesante historia del affair del estanco del tabaco otorgado a Portales, Cea y Cía. Antes de la concesión del estanco a la mencionada empresa y mientras estuvieron en discusión los términos del contrato, algunos presionaron por lo que Salazar llama una solución "productivista", favorecida por el presidente Ramón Freire, que otorgaba el estanco de la importación de tabaco, pero permitía la libre producción, manufactura y comercialización del cultivo interno del tabaco, a la sazón en manos de un gran número de pequeños productores. Otros, entre ellos los futuros

${ }^{11}$ Ibíd., p. 208.

${ }^{12}$ Salazar destaca que en otros países se produjo en vez una alianza entre los artesanos locales y los mercaderes. En cambio en Chile se produjo un divorcio entre estos dos tipos de agentes, que eventualmente condujo a la destrucción de los primeros. 
estanqueros, sostenían que el negocio solamente podía rentar lo que exigía el fisco, si el estanco controlaba todo el negocio (importaciones, producción y manufactura interna, comercialización) y el Estado ponía a disposición del estanco los medios para hacer respetar los derechos correspondientes. Salazar sostiene que el Presidente Freire finalmente fue inducido a firmar el contrato que satisfacía a Portales, Cea y Cía. No obstante lo anterior, esta empresa no fue capaz de controlar a los pequeños productores y manufactureros de tabaco, que se rebelaron masivamente contra las disposiciones del estanco, y tampoco a los contrabandistas extranjeros. Como resultado el negocio produjo pérdidas y dos años después de iniciar sus operaciones se declaró en quiebra. Ése, sin embargo, nos es el final de la historia: los cigarreros locales igual desaparecieron durante la operación de los "estanqueros de recambio", Eyzaguirre Hermanos y Cía. Éstos recibieron la concesión durante la "dictadura de Portales"13, pero más adelante no fueron capaces de competir con una empresa mercantil extranjera que, según Salazar, hacia fines del siglo terminó monopolizando la fabricación de cigarrillos, ahogando las plantaciones nacionales y destruyendo a los "cigarreros".

En otras dos secciones del capítulo cuarto Salazar describe extensamente acciones entabladas por las autoridades para sanear urbanamente secciones de Santiago y otras zonas urbanas. Estas acciones, sin duda, afectaron principalmente a los sectores más populares y en particular al artesanado. No obstante lo anterior, no presenta evidencia convincente que sugiera que el saneamiento descrito - tal como regulaciones que se dictaron con el mismo fin - se hiciera con la finalidad de perjudicar al artesanado en beneficio de la clase mercantil o de la moderna industria. Más adelante se refiere a las "cadenas" del sistema, la guardia cívica y las patentes, ambas usadas por las autoridades — según el autor- como armas en la supuesta "guerra" entre los intereses mercantiles y el artesanado. Es cierto que de pasada se refiere a la importancia que le daba la clase mercantil al respeto por los derechos de propiedad y el orden público. Pero también es cierto que el servicio en la guardia civil era obligatorio para las clases de ingresos más bajos, que según Salazar percibían a la guardia como un instrumento de represión, en cambio las clases más pudientes lo evitaban. Tampoco cabe la menor duda que la reforma al régimen de patentes en los años 1860 — que

${ }^{13}$ Salazar (2009), p. 296. 
pretendió igualar el tratamiento para todo tipo de empresas - perjudicó relativamente a los artesanos y lo hizo en un momento en que el sector ya estaba en dificultades.

Finalmente, en este cuarto capítulo, Salazar analiza el surgimiento y las ideas del proyecto que denomina "social-productivista", asociado en sus comienzos al artesanado y a la figura de Ramón Freire. Los "social-productivistas" partían de la base de un campesinado y un artesanado pobres, de "monopolistas chilenos acumulando su fortuna a costa de la miseria general, pero subordinados a los mercaderes extranjeros $\mathrm{y}$, por tanto, a la necesidad de proteger las actividades productivas del país"14. Más tarde la Sociedad Chilena de Minería, formada en 1844, también se identifica con los intereses productivos, a pesar del origen patricio de sus miembros. En particular, Pedro Félix Vicuña, socio de la mencionada sociedad, impulsor capitalista del "social-productivismo" y redactor de El Minero Nacional, se declaró partidario de no hacer caridad, pero en vez fomentar la producción, y a partir de allí desarrolla una serie de ideas que sugieren la conveniencia de industrializar el país y de terminar con la "aristocracia del dinero", que Salazar recoge ampliamente. Tanto así que este último privilegia las ideas de Vicuña por sobre las de Francisco Bilbao, Antonio Arcos y Victorino Lastarria, a quienes cataloga como "grandes precursores del pensamiento socialista o revolucionario en Chile" y cuyas ideas centrales —a veces más radicales que las de Vicuña- también describe en el libro ${ }^{15}$.

En todo caso, reconoce Salazar que alrededor de 1850 el artesanado no contaba con un programa alternativo al liberal existente. Es entonces Fermín Vivaceta Rupio quien propuso "mejorar la condición de los trabajadores mediante sus propios recursos" y sugiere hacerlo desde el mutualismo. Ello le habría permitido al "social-productivismo" mantenerse vivo, hasta que 50 años después Luis Emilio Recabarren "transfigura" al socialismo las ideas que surgieron en los años 1820. Paralelamente, nos dice Salazar, "por encima de ese proceso (doméstico) campeaba, blandiendo a diestra y siniestra, impertérrito, su autoritarismo (pelucón primero y liberal después) el Estado que el patriciado mercantil había impuesto en 1830. No era ese un Estado de paz, sino uno de guerra, como apuntó el historiador Góngora. Hacía noticia. Intervenía, era injusto, prepotente, se hacía sentir [...] Controlaba sin disputa el

\footnotetext{
${ }^{14}$ Ibíd., p. 397.

${ }^{15}$ Ibíd., pp. 414 y siguientes.
} 
cofre de los tesoros públicos y privados, y por esto, administraba la desigualdad y la injusticia"16.

El quinto capítulo caracteriza brevemente el desarrollo del patriciado mercantil en América Latina y en Perú y Chile, en particular. En unas pocas páginas resume también el tratamiento que se les dio a los pueblos indígenas. Concluye que, junto con el proceso liberalizador, este patriciado mercantil - en cierto modo protegido durante la colonia - debió adaptarse a las condiciones imperantes en mercados competitivos abiertos internacionalmente. Su tesis es que -al revés de lo que sucedió en el caso de Inglaterra - los mercaderes chilenos no fueron capaces de generar una economía dinámica en que todos — productores e intermediarios, capitalistas y trabajadores - prosperaran. En cambio lo que sucedió — según Salazar - es que los mercaderes chilenos "atrapados" entre los consignees extranjeros y los productores, sin poder frente a los primeros, optaron por extraerles rentas a los productores y lo hicieron a tal punto que los "ahogaron", con todas las consecuencias que eso tuvo para los ingresos y empleos de los trabajadores. Escribe: "La parálisis no pudo sino concluir en la aguda crisis social y en la politización de los actores sociales vinculados a la producción para el mercado doméstico, que terminaron, hacia 1910, uniéndose para luchar, no tanto contra el capital extranjero instalado en el país, sino contra la oligarquía criolla (el viejo patriciado, ahora embotellado y decadente) que no halló en el mercado mundial lo que tampoco había encontrado en el mercado virreinal: su propia transformación en burguesía capitalista"17.

El cuerpo del capítulo lo dedica Salazar a analizar diversas formas que utilizaron los mercaderes chilenos para extraer las rentas de productores y trabajadores. Destaca la habilitación de inquilinos (se inició con cobro de arriendo por tierras, que se tornaron expropiadores), la habilitación de labradores (avances en dinero contra entrega de productos y con castigos en caso de no cumplimiento), habilitación de pirquineros (ídem a la anterior, entre otras), el monopolio del crédito público y los mecanismos de extracción monetaria (que iban desde el préstamo realizado por un mercader a tasas "usureras" financiado con

${ }^{16}$ Ibíd., p. 444. En materia política, Salazar relaciona, por supuesto, al "socialproductivismo" con Ramón Freire y con la democracia liberal (los pipiolos) y al régimen imperante durante la mayor parte del siglo XIX, con Diego Portales y los pelucones (conservadores y luego liberales).

${ }^{17}$ Salazar (2009), p. 503. 
la hipoteca de una propiedad en alguna institución de crédito "oficial", hasta la "creación" de dinero en base a "fichas" y más adelante, en la época de la banca libre, por intermedio de la emisión de dinero). El relato de estos casos sugiere - al referirse a ejemplos concretos- el carácter normalmente abusivo de estas prácticas y concluye: "El conjunto de estos mecanismos operó como un poder "fáctico", no-constitucional, que retrasó por un siglo la aparición de un sistema bancario y una tasa de interés regulada; por casi dos siglos la aparición de una legislación social capaz de neutralizar el sesgo esclavizante de la plusvalía total, y que suspendió a plazo indefinido la consolidación de un verdadero 'empresariado industrial' en el país".

El capitulo seis analiza el evidente proceso de industrialización chileno a partir de mediados del XIX, promovido en parte importante por mercaderes extranjeros. Corresponde a la evolución natural de las actividades de las casas mercantiles extranjeras, facilitada por el artesanado existente, y se caracterizó por ser diversificada y pujante. Hacia 1885 se instalaron incluso industrias productoras de bienes de capital. Salazar sostiene que esta industrialización se basó, inicial y principalmente, en la importación de maquinaria extranjera (el principal negocio de los mercaderes extranjeros). Agrega que "el aprovisionamiento comercial de maquinaria devino en el talón de Aquiles del movimiento industrial chileno, pues [...] erosionó letalmente la rama de Fundiciones \& Ingeniería, motor central del desarrollo industrial" ${ }^{18}$. Este capítulo presenta también un interesante y detallado relato del desarrollo de cuatro ramas industriales en Chile: vestuario y confección, madera y muebles, imprenta y papeles, y fundiciones metal-mecánicas.

Finalmente, en el séptimo capítulo Salazar analiza la relación entre el conglomerado extranjero y la oligarquía nacional. Sostiene que a raíz de la crisis de 1824-1825, que indujo a las empresas inglesas a intensificar su esfuerzo exportador, éstas reemplazaron los consignees por subsidiary houses, lo que generó la oportunidad a los empresarios nacionales de producir bienes exportables, sobre todo agrícolas y mineros, para ser comercializados por estos mercaderes extranjeros. Afirma que "A comienzos del siglo XX el conglomerado capitalista extranjero constituía, de hecho, el verdadero motor del capitalismo chileno, y sus socios residentes, la verdadera burguesía modernizadora del país"19.

\footnotetext{
${ }^{18}$ Ibíd., p. 669.

${ }^{19}$ Ibíd., p. 674.
} 
Agrega que los capitales de estas empresas extranjeras "en una medida importante, se formaron teniendo como base las utilidades obtenidas dentro del país" 20 .

En este último capítulo Salazar describe también el auge y ocaso de los merchant bankers chilenos. Si Salazar describe las operaciones del conglomerado extranjero basado en la descripción de las operaciones de varias de las más importantes subsidiary houses, caracteriza a los merchant bankers chilenos centrándose en la trayectoria del grupo Edwards. No obstante lo anterior, pasa también rápida revista al caso de otras familias, haciendo notar que en general su rol empresario no ha perdurado en el tiempo. Atribuye esta decadencia a que los empresarios nacionales privilegiaron "la banca y las especulaciones financiaras y políticas" por sobre la "producción manufacturera-industrial y la comercialización externa", inclinándose por "la vida opulenta y la degustación plena de su elitismo"21. Otra característica de los merchant bankers chilenos que destaca y describe Salazar en este capítulo es el constante acoso que éstos hicieron sobre el Estado. Se refiere explícitamente a "los constantes pedidos de prórroga del pago de deudas con instituciones oficiales (Casa de Moneda, Aduana), pedidos de autorización de instalación de muelles propios en desmedro de los oficiales y del uso de trabajadores del Gremio de Jornaleros, simulación o elusión de las normas legales de la emisión de billetes, solicitudes de suspensión de la ley para no pagar impuestos o facilitar el comercio de importación o exportación, solicitando préstamos en oro y/o libras esterlinas con cargo a los empréstitos externos gestionados por el gobierno y a devolverse en moneda nacional, y gestionando préstamos al Estado (en billetes de banco) a ser reembolsados por él en Londres (en oro y/o libras esterlinas)"22.

El libro termina con una breve revisión del juicio crítico que hicieran algunos historiadores, economistas y empresarios, principalmente extranjeros, sobre la economía chilena durante el siglo XIX y comienzos del siglo XX. Naturalmente dichos juicios coinciden con la posición del autor en la existencia de una burguesía que no invirtió lo necesario y en la falta de una adecuada política monetaria y de industrialización. El autor concluye responsabilizando —en último término - al ideario portaliano de tales falencias.

\footnotetext{
20 Ibíd., p. 694.

21 Ibíd., p. 747.

22 Ibíd., pp. 748 y siguientes.
} 


\section{Metodologías y hechos: ¿fue realmente tan malo el comportamiento económico de Chile en el siglo XIX?}

El comentario sobre el libro de Gabriel Salazar requiere una reflexión, aunque sólo sea muy breve, de carácter metodológico, dado que el libro fue escrito por un historiador y lo comenta un economista, pero sobre todo porque las percepciones de uno y otro difieren.

En la actualidad en ambas disciplinas el investigador debe plantear una tesis. El historiador podrá preguntarse, como lo hizo Salazar, cómo un orden político tan célebre, apolíneo y patriótico como el portaliano, al mismo tiempo que tan alabado por las clases dirigentes durante gran parte de nuestra historia, pudo producir un resultado económico y social tan desgarrador como el que se observó a comienzos del siglo $\mathrm{XX}$ en Chile y puede luego sostener que fue consecuencia del régimen portaliano. El economista, en cambio, tenderá a plantear su tesis en base a la teoría económica y con una fuerte carga causal. Por ejemplo, sostendrá que la tasa de inflación que se observa en Chile a partir de 1878 y hasta 1925 se originó en el importante déficit fiscal financiado con emisiones.

El historiador, habiendo articulado su tesis, acopia hechos que, en principio, puede clasificar en aquellos que soportan su tesis y en otros que rechazan cualquier conjetura alternativa ${ }^{23}$. Una característica del trabajo histórico es el uso de datos obtenidos de fuentes primarias. Recopilados los hechos, el historiador debe hacer el relato más convincente posible. Como norma no hay una "prueba" rigurosa, en el sentido en que se hace en las ciencias exactas, sino el trabajo será juzgado por sus pares en base a la calidad, profundidad y cobertura de los datos y hechos aportados y por la forma — más o menos convincente- de relatar la historia.

El economista, en cambio, al hacer historia económica formulará un modelo, generalmente de carácter algebraico, en que relaciona las variables pertinentes en base a la teoría económica. Con ello se logra hacer en cada caso una proposición lógica, formal y rigurosa, que luego se puede someter a una prueba estadística. En el caso de la inflación, podría ser por ejemplo que (1) $\prod=\mu+v-\rho$, es decir, la inflación es igual

${ }^{23}$ Podría también tener hechos contundentes que refutan su tesis. En la práctica ello rara vez ocurre, dado que generalmente el investigador - historiador o economista - acopia los datos antes de formular su tesis en forma precisa. 
a la tasa de emisión de dinero más el cambio relativo en la velocidad de circulación del dinero y menos la tasa de crecimiento del ingreso, y (2) $(\mathrm{T}-\mathrm{G}) / \mathrm{M}=\mu$, es decir, que el déficit fiscal -impuestos menos gasto público - como porcentaje de la cantidad de dinero es igual a la tasa de emisión. Luego, utilizando series de datos de inflación, emisión, velocidad de circulación del dinero, tasa de crecimiento del ingreso, impuestos y gasto fiscal, que generalmente provienen de fuentes secundarias, se verifica si la tesis no es rechazada estadísticamente. Si no lo es, se tiene una buena explicación del fenómeno.

Por lo anterior, la tendencia natural del economista es someter cualquier juicio a un test estadístico. Por ejemplo, ¿fue tan desastroso el comportamiento de la economía chilena en el siglo XIX como sostiene Salazar? Si no fuera así, se invalida su tesis. Nadie discute que a fines de ese siglo hubo mucha pobreza en el país — por algo es la época en que surgió la "cuestión social"-, pero eso no significa que el sistema haya sido inadecuado. Por ejemplo, un sistema alternativo podría haber dado aun peores resultados.

Una manera útil de evaluar el comportamiento económico de un país es compararlo con el de otros. Es eso lo que hizo Lüders (1998), en que no sólo comparó la evolución del PIB per cápita de Chile con el de otros países individualmente, sino que —utilizando análisis determinante aplicado al comportamiento de tres variables simultáneamente (PIB per cápita, exportaciones a PIB, y tasa de inflación) - verificó que el comportamiento económico de Chile en los sub-periodos identificados fue estadísticamente distinto —en algunos "mejor" y en otros "peor"a pesar de que para todo el período 1810-1995 no resultó serlo.

Acá simplemente rescatamos la comparación del PIB per cápita de Chile con aquel de EE.UU. en un gráfico actualizado (Gráfico $\mathrm{N}^{\circ} 1$ ). Un resultado similar se obtiene en una comparación del PIB per cápita de Chile con el del "resto del mundo" o el agregado de una muestra de países de Europa o incluso de América Latina ${ }^{24}$.

Es evidente que la tendencia del crecimiento económico de Chile en el siglo XIX y hasta 1910 fue al menos satisfactorio, considerando que - si algo - el PIB per cápita de tendencia de Chile creció a una tasa mayor que el de los EE.UU.

¿Podría haber crecido más con una política de fomento a la industrialización como la que sugiere Salazar en su libro? La teoría dice

${ }^{24}$ Lüders (1998). 
GRÁFICO No ${ }^{\circ}$ : PIB POR PERSONA DE CHILE EN RELACIÓN CON EL DE LOS EE.UU. (Porcentajes)

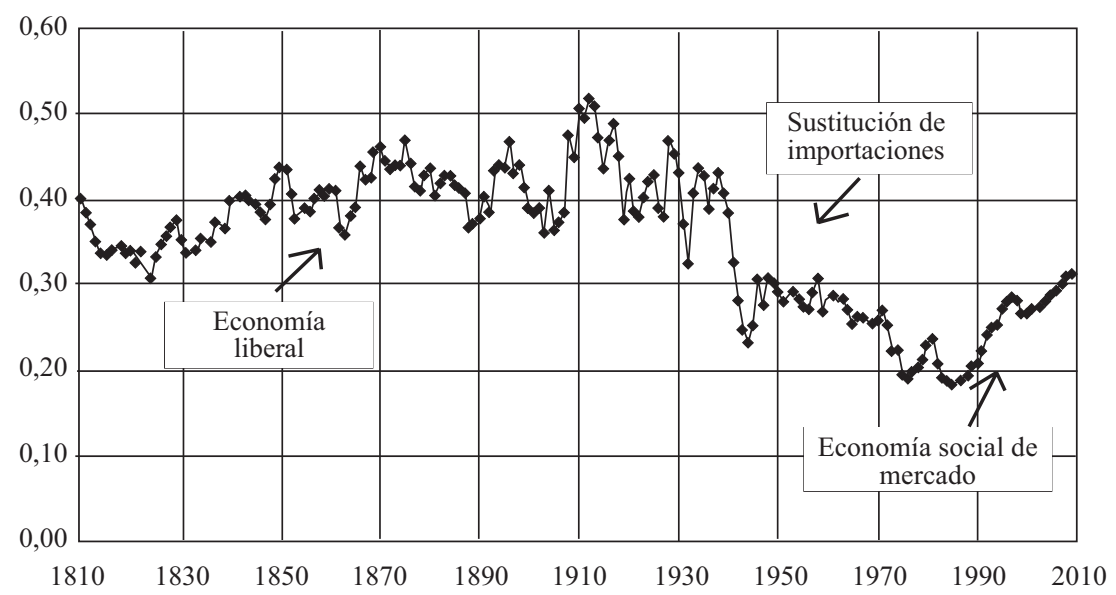

Fuente: J. Díaz, R. Lüders y G. Wagner, La República en Cifras, 2010. EH Clio LabIniciativa Científica Milenio. URL: http://www.economia.puc.cl/cliolab.

lo contrario, dado que se estarían mal asignando los recursos. Y la experiencia chilena es lapidaria. Cuando se aplicó una política de sustitución de importaciones, y tal como lo muestra el Gráfico $\mathrm{N}^{0} 1$, el PIB per cápita de Chile creció mucho menos que el de los EE.UU.

Pero ¿no habrá aumentado la pobreza? La evidencia tentativa que se muestra en el Gráfico $\mathrm{N}^{\mathrm{o}} 2$ —en adelante con datos de 1850 de Leandro Prados de la Escosura - sugiere lo contrario. La pobreza en Chile ha caído en forma persistente, lo que es — desde el punto de vista teórico- coherente con un país que crece en forma relativamente rápida en lo económico.

Si el país tuvo una evolución satisfactoria del PIB per cápita y una rápida reducción de los niveles de riqueza, ¿cómo explicar entonces el descontento social existente a fines del siglo XIX y comienzos del $\mathrm{XX}$ ? Una posible explicación es la desigual distribución del ingreso (ver Gráfico $\mathrm{N}^{\mathrm{o}} 3$ ). Medidos por el coeficiente de Gini, los niveles de desigualdad de ingresos en el período de entreguerras llegaron a su máximo histórico. Esto es coherente con un nivel de ingreso promedio creciente y salarios reales estancados o incluso decrecientes, ambos observados en Chile durante las últimas décadas del siglo XIX y los primeros años del siglo XX. 
GRÁFICO N ${ }^{\circ}$ 2: CHILE: PORCENTAJE DE LA POBLACIÓN CHILENA DEBAJO DE LA LÍNEA DE POBREZA

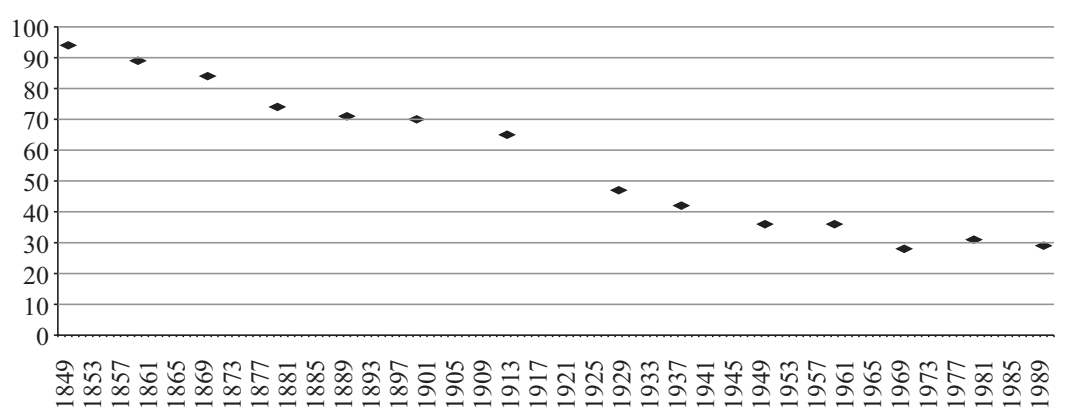

Fuente: L. Prados (2005).

GRÁFICO No 3: CHILE: DISTRIBUCIÓN DEL INGRESO

(Coeficiente de Gini)

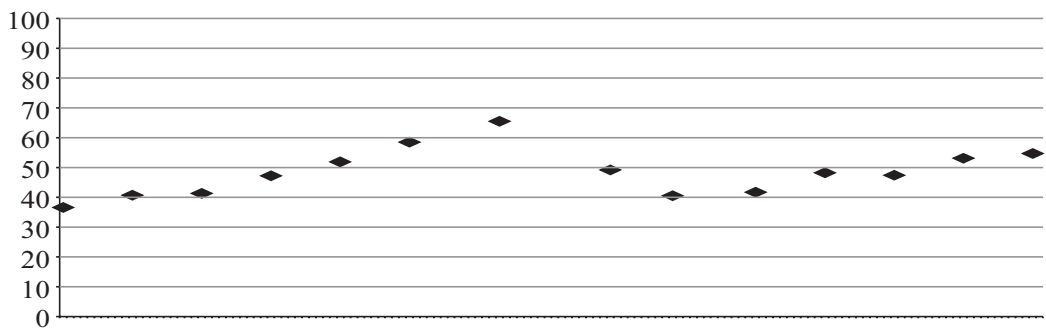

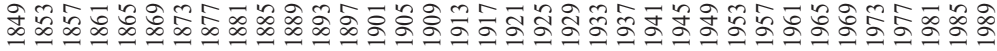

Fuente: L. Prados (2005).

Como conclusión de esta parte, la evidencia empírica más sistemática no parece avalar los juicios de Gabriel Salazar. Al contrario de lo que este último sostiene implícitamente en su libro, en el siglo XIX Chile creció a una tasa razonable y la reducción de la pobreza fue significativa - es decir, se produjo una mejora generalizada de bienestar - a pesar de que la distribución del ingreso se hizo más desigual. Es posible - pero no probable - que otra política económica distinta a la de una economía de mercado abierta al comercio internacional podría haber 
dado mejores resultados. De ser así, la misma evidencia empírica chilena sugiere que en ningún caso tal política habría sido el proteccionismo y la industrialización forzada.

\section{Algunos comentarios específicos}

El libro de Salazar representa un esfuerzo notable de acumulación de antecedentes, de ordenamiento de los mismos y de articulación de una interpretación histórica de la experiencia que representan. La información que contiene el libro es además muy útil para futuras investigaciones. Aunque en algunas secciones hay quizás datos superfluos, innecesarios para el trabajo de interpretación que se hace en el texto. Esto sucede por ejemplo en el capítulo III, sección 2. El libro contiene también una serie de "cuentos", relatos o episodios interesantísimos, ya señalados en una sección anterior del comentario y, para el lector no profesional, tienen la virtud de estar bien escritos y ser de lectura fácil.

A medida que se avanza en la lectura del libro se tiene la sensación de que éste fue escrito a partir de un marco conceptual y valórico no explicitado y mucho menos analizado, que sin embargo pudo haber sesgado los resultados de la investigación. En particular, pareciera que para el autor, por ejemplo, (1) el librecambismo es malo y la industrialización es buena, y (2) los mercaderes son malos y los artesanos son buenos ${ }^{25}$. Algo así como "the good guys against the bad guys". La historia entonces se teje en torno a estos valores, pudiendo haber sido mucho más fructífero para el objetivo declarado de la obra, destacar las fuerzas o variables económicas que pueden explicar el comportamiento económico observado. Por ejemplo, el autor inserta en la página 75 un párrafo que no puede sino reflejar su opinión y que se entrega sin el necesario respaldo de hechos. Dice: "El oro mercantil no era más que oro robado. Robado ayer, hoy, mañana, todos los días. En su origen productivo, en su traspaso comercial, en su atesoramiento final. Al punto que ya no parecía metal, sino robo permanente. Cubierto por la endémica miseria de todos los que le codiciaban y tocaban."

${ }^{25}$ Salazar es igualmente tajante en sus opiniones políticas, que expresa con gran fuerza en el libro, sin dejar lugar a dudas sobre sus simpatías. Por ejemplo, no habla del gobierno de O'Higgins sino de la dictadura de O'Higgins. También se refiere a la dictadura mercantil o a la dictadura de Portales. Véase p. 280. 
El libro no es completo, en el sentido que ignora para todos los efectos prácticos -o los trata en forma muy indirecta- episodios absolutamente claves de la historia económica de Chile en el siglo XIX. Resalta en especial la falta de al menos una sección sobre la Guerra del Pacífico y la anexión de los territorios calicheros. La riqueza del salitre tuvo efectos profundos en nuestra sociedad. Acentuó el carácter "rentista" del chileno, cambió marcadamente la estructura productiva del país, contribuyó a exacerbar los problemas sociales ya existentes, y produjo "enfermedad holandesa". Es posible argumentar que esta última a su vez generó las presiones proteccionistas que explican el declive relativo de la economía chilena después de 1910.

Hay varias partes del libro que requieren $-\mathrm{y}$ en que se haceun análisis técnico-económico. No obstante, queda en evidencia que el autor — un historiador - no posee, ni tiene por qué poseer, las competencias necesarias. Describiremos acá sólo algunos ejemplos:

(1) El caso de la escasez de dinero, que es representativo del tipo de análisis monetario que se hace en el texto. El autor sostiene que mientras más dinero atesoraban los mercaderes, menos dinero metálico había para circulación interna ${ }^{26}$. Esto no fue cierto en el caso del sistema monetario bi-metálico chileno, dado que la escasez inicial de metálico por acaparamiento redujo marginalmente los precios de los productos y servicios en Chile, y entonces se importó menos y se exportó más, y la diferencia la pagaron los extranjeros en metálico. Mediante este proceso la oferta de metálico (dinero) se ajustó a su demanda ${ }^{27}$. En realidad el problema en esos años fue la escasez de monedas de plata - que eran las divisionarias que se utilizaban para las transacciones diarias - y dicha escasez se produjo porque Chile tuvo un sistema monetario bi-metálico. Eso obligó a fijar una relación de precios del oro y la plata en las monedas y cuando cambiaba el precio del oro expresado en plata en el mercado, se generaban los incentivos para exportar, ya sea oro o plata.

(2) El caso de los pasajes del libro en que se habla de rentabilidades, tasas de interés, etc. En la página 679 del libro, Salazar expresa:

${ }^{26}$ Salazar (2009), p. 46.

${ }^{27}$ En el libro Salazar, al referirse al atesoramiento de metálico por parte de los pudientes en sus casas, sostiene que "rodeadas - las casas - en sus cuatro costados por una sociedad empobrecida y a la vez enardecida, precisamente por la escasez monetaria que esas casas generaban en ella". Como el atesoramiento de metálico en esos años no podía generar escasez de metálico excepto muy transitoriamente, la causa del empobrecimiento mencionada hay que buscarla por otro lado. 
"Las ventas anuales de acuerdo a la sucinta información que hay al respecto, solían ser equivalentes al capital pagado, ya que era frecuente que alcanzaran cifras de 70\% del mismo. Tal margen de utilidad era incomparable con la de un Hacendado del Valle Central, por ejemplo, cuya tasa de ganancia agrícola oscilaba entre $4 \%$ y $5 \%$ anual del valor de la propiedad" (cursivas agregadas). En este caso obviamente el autor confunde ventas con utilidades, que son cosas distintas. La confusión, no obstante, genera en el lector no experto la sensación de que los mercaderes hacían enormes utilidades. Lo más probable es que la competencia entre mercaderes haya generado tasas de retorno del negocio compatibles con aquellas de otros sectores, ajustadas por riesgo por supuesto.

(3) El caso del monopolio que supuestamente habrían tenido los merchant bankers chilenos sobre el crédito y la moneda ${ }^{28}$, que también se repite en el libro. Tal monopolio nunca existió, ni siquiera en la época de la banca libre (1865-1878). Ciertamente hubo competencia mientras el país se encontró bajo el patrón bi-metálico y todos tuvieron acceso a la acuñación de monedas; la competencia aumentó cuando los comerciantes emitieron fichas y siguió existiendo luego que se creó la banca de emisión.

(4) Y El caso de los incentivos y el mercado, en que Salazar sostiene que: "Fue el tiempo en que el capital comercial-financiero estaba subsumido, alienado y personalizado en el patrimonio familiar. Es decir, una forma de capital-dinero (de comercio) que se regía sobre todo por un afán privado (subjetivo) de enriquecimiento, más que por la ciencia (objetiva) del mercado". Cuesta realmente entender el párrafo, pero Salazar pareciera horrorizarse por el afán de lucro de esas familias, pero ¿no es lo normal —además de deseable — que los agentes económicos traten de maximizar beneficios y lo hagan en el ámbito de los mercados competitivos? Si eso sucede, lo más probable es que estemos en presencia de una economía eficiente y próspera.

\section{Conclusiones}

Gabriel Salazar nos deleita una vez más con uno de sus libros, esta vez con Mercaderes, Empresarios y Capitalistas. El libro respeta la tradición de sus principales obras previas, pero realiza ahora su análisis

\footnotetext{
${ }^{28}$ Salazar (2009), pág. 760.
} 
de la sociedad chilena desde la óptica de la clase mercantil. Se propone entender por qué Diego Portales -ícono de esa clase durante la primera mitad del siglo XIX - es un personaje tan respetado y alabado por la clase dirigente chilena ahora y en el pasado, a pesar de haberle imprimido su particular sello a la economía chilena, que la llevó al fracaso a comienzos del siglo XX.

Salazar no contesta con su libro toda la pregunta que se hizo, pero sí nos "pinta" un cuadro coherente con la idea de fracaso del modelo portaliano. De acuerdo al autor, la apertura de la economía después de la independencia atrajo a mercaderes extranjeros, que se asociaron formal o tácitamente con mercaderes chilenos. Muy grosso modo, los primeros realizaban el comercio exterior e importaban bienes industriales, mientras que los segundos se responsabilizaban del acopio de bienes mineros y agrícolas. Los mercaderes chilenos, sin embargo, no produjeron estos últimos bienes sino que los encargaban o acopiaban, ni tampoco fueron capaces de generar las condiciones que permitieran al país tener un crecimiento económico autosostenido alto, dedicándose principalmente a la intermediación financiera y comercial. Para poder obtener márgenes interesantes, se vieron "forzados" — nos dice el autor- a extraer las rentas de las personas que trabajaron con o para ellos, destruyendo en el proceso puestos de trabajo y fuentes de crecimiento económico. Los mercaderes utilizaban además todas las mañas posibles para extraer rentas del Estado. Salazar diría que el librecambismo y la represión portaliana no produjeron en el siglo XIX la suficiente industrialización - a pesar de un brote interesante que hubo hacia final de siglo- para generar condiciones sociales aceptables en el país.

Pero lo que Salazar constata en realidad es que bajo las condiciones institucionales que describe, Chile no se había desarrollado en el siglo XIX y que en cambio había estallado la "cuestión social". Sin embargo, para juzgar el grado de desarrollo alcanzado y así también al modelo institucional y de política económica de la época, se requiere un patrón de medida. Ése es el ejercicio realizado en Lüders (1998) que, actualizado, muestra que el país probablemente tuvo en el siglo XIX un comportamiento económico incluso algo superior al de los EE.UU. $\mathrm{Si}$ a eso se agrega que la pobreza se redujo muy significativamente, el aumento del bienestar en Chile debe haber sido muy significativo. Es decir, los datos agregados rechazan la parte medular de la hipótesis de Salazar. 
A pesar de lo anterior, a pesar del sesgo conceptual y valórico con que el autor encara el tema, y a pesar de la evidente ausencia del uso de teoría económica que pudiera haber podido orientar el trabajo de investigación y análisis, Mercaderes, Empresarios y Capitalistas es una obra monumental que hace un importante aporte al entendimiento de la sociedad chilena en el siglo XIX.

\section{REFERENCIAS}

Lüders, R. (2008) “Crecimiento Económico de Chile: Lecciones de la Historia”. "Revista de Economía y Administración", Pontificia Universidad Católica de Chile.

- (1998). "The Comparative Performance of Chile 1810-1995". Estudios de Economía, Vol. $25 \mathrm{~N}^{\circ}$ 2, Santiago.

Prados, L. (2005). "Growth, Inequality and Poverty in Latin America: Historical Evidence, Controlled Conjectures". Universidad Carlos III Working Paper N ${ }^{\circ}$ 05-41(04). 